\title{
PENGEMBANGAN SISTEM INFORMASI MANAJEMEN SURAT POLITEKNIK GORONTALO
}

\author{
Roys Pakaya ${ }^{1}$, Ruly S. Sinukun ${ }^{2}$, Abdul Rahman Tapate ${ }^{3}$ \\ ${ }^{1}$ e-mail: royspakaya@poligon.ac.id, 2,rulysinukun@poligon.ac.id, ${ }^{3}$ abdulrahmantapate01@gmail.com \\ ${ }^{1}$ Dosen Prodi Teknik Informatika, Politeknik Gorontalo, \\ ${ }^{2,}$ Dosen Prodi Teknik Informatika, Politeknik Gorontalo, ${ }^{3}$ Dosen Prodi Teknik Informatika, Politeknik Gorontalo
}

\begin{abstract}
Along with the development of technology is increasing rapidly. This we can see in everyday life. Everything has been done by a machine without exception starting from small things to large ones. For example, human needs in the office work sector have all been done with computer machines. This is due to the original nature of humans who are looking for something more effective in carrying out something. To help others to be more effective in this work is what makes technology increasingly growing.

In-office work, we often deal with correspondence where we are told to make letters. The letter is part of the tool or communication media in the form of writing that contains information, messages, requirements, or responses according to the wishes of the writer of the letter. Letters are written communication devices. Today letters are considered the most efficient, effective, economical and practical written communication tool. The role of letters is even more important, especially in official letters, such as letters issued by organizations/institutions.

This rapid development is very good if put to good use. This has been exemplified in previous research by an application titled mail management information system at POLITEKNIK GORONTALO 2018. In this study, the focus is on configuring conventionally made letters so that data security is safe and potential data loss does not occur. This is still a problem for the intonation because the existing applications still do not pay attention to the matter of making a letter. Making a letter is indeed a problem in an instant, especially on a campus in which there are various supporting elements. To answer this problem the author made an application development management information system of Gorontalo polytechnic letters. Which emphasizes the problem of making letters and automatic letter numbering so that it is easy to search for letters. Then with this application, the agency will get ease in managing incoming and outgoing mail.
\end{abstract}

Intisari- Seiring dengan perkembangan teknologi meningkat dengan pesatnya. Hal ini dapat kita lihat pada kehidupan sehari-hari. Segala sesuatu sudah dikerjakan oleh mesin tanpa terkecuali dimulai dari hal-hal yang kecil sampai dengan besar sekalipun. Sebagai contoh kebutuhan manusia dalam sektor pekerjaan kantor semua telah dilakukan dengan mesin komputer. Ini dikarenakan sifat asli manusia yang mencari sesuatu yang lebih efektif dalam melaksanakan sesuatu. Dengan niat membantu orang lain agar bisa lebih efektif dalam pekerjaan inilah yang membuat teknologi itu semakin hari semakin berkembang.

Dalam pekerjaan di kantor, kita seringkali berhadapan dengan surat - menyurat dimana kita disuruh untuk membuat surat. Surat merupakan bagian dari alat atau media komunikasi yang berupa tulisan yang berisi informasi, pesan, persyaratan, atau tanggapan sesuai keinginan sang penulis surat. Surat merupakan sarana komunikasi tertulis. Dewasa ini surat dianggap sebagai alat komunikasi tulis yang paling efisien, efektif, ekonomis, dan praktis. Peranan surat lebih penting lagi, terutama dalam surat resmi, seperti surat yang dikeluarkan oleh organisasi/lembaga.

Perkembangan yang pesat ini sangat baik apabila dimanfaatan dengan sebaik baiknya. Ini telah dicontohkan pada penelitian terdahulu oleh aplikasi yang berjudul sistem informasi manajemen surat di POLITEKNIK GORONTALO 2018. Dalam penelitian tersebut menitik beratkan kepada pengasipan surat yang konfensional dijadikan digital agar keamanan data menjadi aman dan potensi kehilangan data tidak terjadi. ini masih menjadi maslah tersendiri bagi intanasi tersebut dikarenakan aplikasi yang ada masih belum memperhatikan soal pembuatan surat. Pembuatan surat memang menjadi masalah tersendiri dalam sebuah instanasi terutama pada sebuah kampus yang didalamnya terdapat berbagai macam unsur pendukung.

Untk menjawab permasalahan ini penulis membuat sebuah pengembangan aplikasi sistem informasi manajemen surat politeknik gorontalo. Yang menitik beratkan kepada permasalahan pembuatan surat serta penomoran surat yang otomatis sehinggah mudah dalam pencarian surat. Kemudian dengan aplikasi inilah instansi akan mendapatkan kemudahan dalam mengelolah surat masuk dan keluar.

Kata Kunci- Pengembangan, sistem, manajemen, surat 


\section{PENDAHULUAN}

Dewasa ini perkembangan teknologi meningkat dengan pesat. Ini bisa dibuktikan dengan hampir semua kebutuhan manusia dalam sektor pekerjaan kantor telah di lakukan dengan komputer. Ini dikarenakan sifat asli manusia yang mencari sesuatu yang lebih efektif dalam melaksanakan sesuatu. Dengan niat membantu orang lain agar bisa lebih efektif dalam pekerjaan inilah yang membuat teknologi itu semakin hari semakin berkembang.

Perkembangan yang pesat ini sangat baik apabila dimanfaatan dengan sebaik baiknya. Ini telah dicontohkan pada penelitian terdahulu oleh aplikasi yang berjudul sistem informasi manajemen surat di POLITEKNIK GORONTALO 2018. Dalam penelitian tersebut menitik beratkan kepada pengasipan surat yang konfensional dijadikan digital agar keamanan data menjadi aman dan potensi kehilangan data tidak terjadi. ini masih menjadi maslah tersendiri bagi intanasi tersebut dikarenakan aplikasi yang ada masih belum memperhatikan soal pembuatan surat.

Pembuatan surat memang menjadi masalah tersendiri dalam sebuah instanasi terutama pada sebuah kampus yang didalamnya terdapat berbagai macam unsur pendukung. Diantara adalah unsur Dosen, Administrasi, Teknisi, Laboran dan Mahasiswa (BEM). Pembuatan surat yang akan dibuat oleh Administrasi yang berada di bagian umum dan kepegawaian, memang kelihatannya tidak menjadi masalah dikarenakan itu sudah menjadi tugas mereka. Namun ketika surat tersebut dibuat oleh bagian atau unsur yang lain maka akan menemukan kendala yang cukup menjadi pemikiran bersama. Antara lain adalah soal aturan baku surat sebuah instansi yang biasanya di tandai dengan kop Surat. Kemudian soal penomoran surat yang maih harus melakukan permintaan nomor surat kepada bagian umum dan kepegawaian.

Oleh karena masalah yang terjadi di atas maka penulis akan menjawab permasalahan itu dengan membuat sebuah pengembangan aplikasi sistem informasi manajemen surat politeknik gorontalo. Yang menitik beratkan kepada permasalahan pembuatan surat serta penomoran surat yang otomatis sehinggah mudah dalam pencarian surat. Kemudian dengan aplikasi inilah instansi akan mendapatkan kemudahan dalam mengelolah surat masuk dan keluar.

\section{TINJAUAN PUSTAKA}

A. Kerangka Berpikir

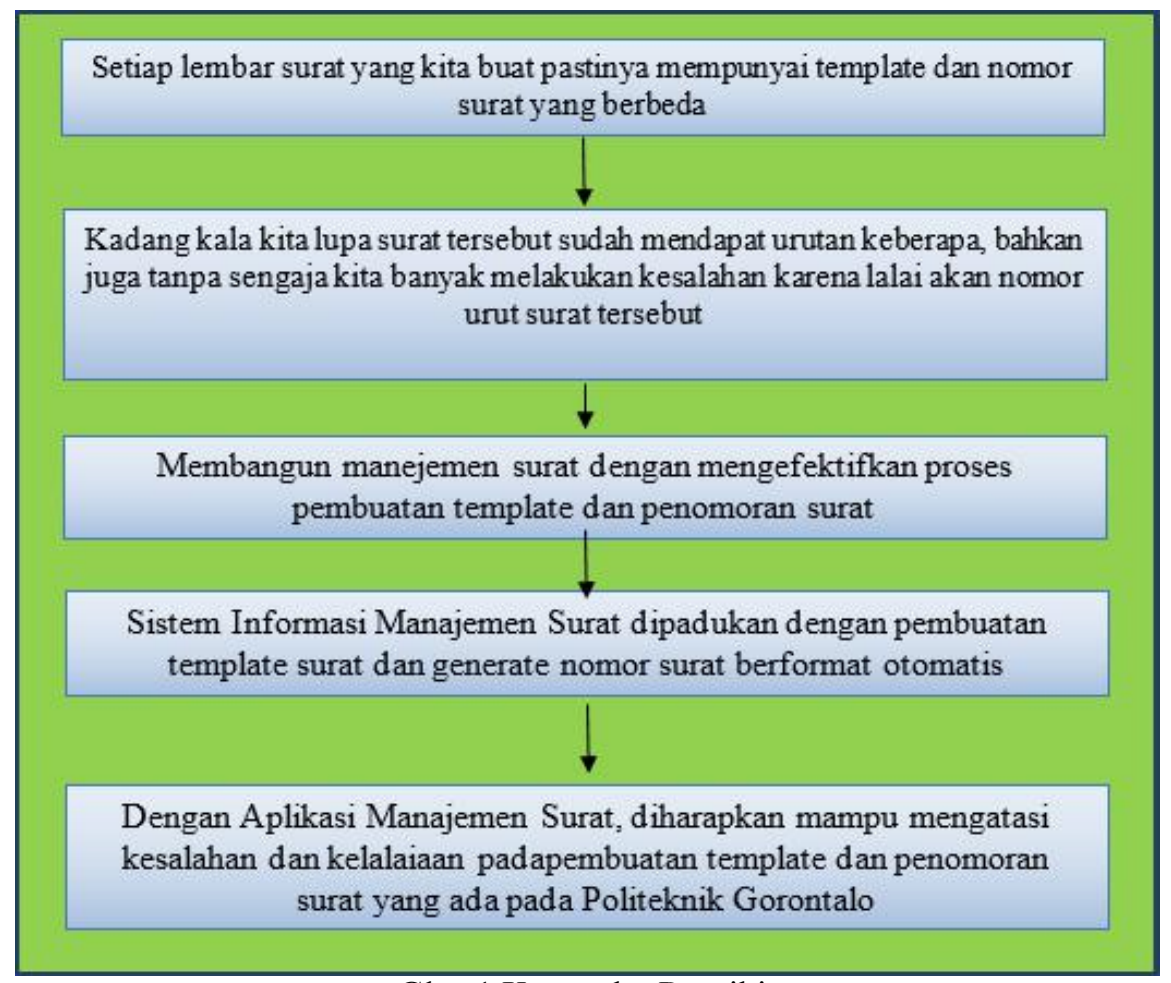

Gbr. 1 Kerangka Berpikir

B. Pengertian Sistem Informasi

Pada umumnya sistem informasi merupakan sebuah sistem yang ada pada sebuah organisasi dimana didalamnya terdapat kombinasi yang terdiri dari kumpulan orang, fasilitas, teknologi bahkan cara kerja atau metode sehingga menciptakan alur sebuah komunikasi serta pemprosesan beragam tipe kejadian internal maupun eksternal yang dapat dijadikan sebagai sebuah dasar dalam penentuan keputusan berdasarkan informasi yang terdapat pada sistem tersebut.

Sistem Informasi pada umumnya dapat terbentuk dengan beberapa kegiatan operasi tetap berikur ini :

1. Pengumpulan data

2. Pengelompokan data 

3. Penghitungan data
4. Analisa topik masalah
5. Penyajian laporan

Sedangkan sasaran dari suatu sistem informasi yakni :

1. Dengan adannya sistem informasi maka penyelesaian tugas atau pekerjaan akan semakin meningkat

2. Proses pengerjaan tugas atau pekerjaan akan mempunyai nilai efektivitas yang tinggi secara keseluruhan

3. User dituntut untuk lebih produktif supaya memperoleh output yang berkualitas

4. Sistem yang dibuat harus bersifat "easy to use" atau mudah penggunaannya

5. Out yang berkualitas akan mendatangkan pendapatan atau keuntungan yang lebih besar daripada biaya pembuatan dan maintenance (perawatan) sistem itu sendiri

6. Efektifitas ekonomi dapat meningkat.

Secara garis besar, sistem informasi bisa diartikan sebagai sistem yang saling terintegrasi satu sama lain secara penuh atau optimal sehingga pengolahan, penyimpanan, pengelolaan, pemprosesan dan penyajian informasi suatu perusahaan atau organisasi dapat tersaji dalam berbagai jenis informasi yang akurat sehingga nantinya dapat dijadikan sebagai acuan penentu keputusan guna berhasil mencapai tujuan yang telah disepakati bersama.

\section{Pengertian Surat}

Surat adalah sarana komunikasi untuk menyampaikan informasi tertulis oleh suatu pihak kepada pihak lain. Fungsinya mencakup lima hal:

1. Sarana pemberitahuan, permintaan;

2. Buah pikiran, dan gagasan;

3. Alat bukti tertulis; alat pengingat; bukti historis;

4. Pedoman kerja.

Pada umumnya, dibutuhkan perangko dan amplop sebagai alat ganti bayar jasa pengiriman. Semakin jauh tujuan pengiriman surat maka nilai yang tercantum di perangko harus semakin besar juga.

\section{Code Igniter}

Penggunaan CodeIgniter pada pengembangan system informasi manajemen surat di Politeknik Gorontalo akan menghasilkan suatu struktur pemrograman yang sangat rapi, baik dari segi kode maupun struktur file phpnya. Struktur aplikasi yang rapi tentu sangat diperlukan dari sebuah aplikasi. Misalnya, jika terjadi suatu error dalam aplikasi, dengan code yang rapi kita dapat dengan mudah menemukan kesalahan tersebut. Bukan hanya itu, bayangkan suatu saat aplikasi yang kita bangun membutuhkan fungsi-fungsi lain yang sangat penting, tentu akan diperlukan pengembangan lebih lanjut. Dan sekali lagi, hal itu juga sangat memerlukan struktur coding yang rapi. Dengan menggunakan CodeIgniter, untuk mewujudkan struktur kode yang rapi sangat-sangat mungkin terjadi. Hal itu dikarenakan CodeIgniter dibangun berbasis MVC (Model, View, Controller) yang memisahkan antara tampilan dan logic aplikasi.

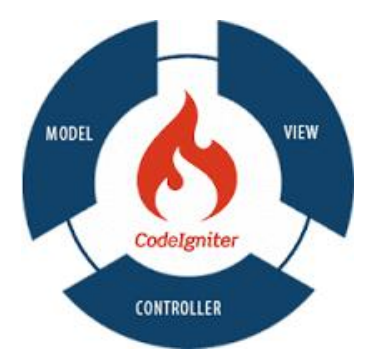

\section{Gbr 2. Model View Controller CodeIgniter}

1. Model adalah bagian yang bertanggung jawab terhadap operasi database, baik itu create, read, update ataudelete. Berisi fungsi-fungsi operasional database yang dapat dipanggilkan oleh Controller.

2. View adalah bagian yang menangani tampilan. bagian inilah yang bertugas untuk mempresentasikan data kepada user. Ia berbentuk struktur HTML yang berisikan variabel data yang dikirimkan oleh Controller.

3. Controller adalah bagian yang mengatur hubungan antara Model dan View. Ia adalah otak dari kinerja aplikasi. Ia terdiri dari fungsi-fungsi yang bersifat operasional dan logikal. Saat ada request yang masuk, ia akan menangani dan memprosesnya untuk kemudian ditampilkan dalam View.

\section{E. Basis Data}

Tujuan dari pengunaan basis data pada pengembangan sistem informasi manajemen surat di Politeknik Gorontalo adalah:

1. Memastikan bahwa data dapat dipakai di antara pemakai untuk berbagai aplikasi.

2. Memelihara data baik keakuratan maupun kekonsistenannya. 
3. Memastikan bahwa semua data yang diperlukan untuk aplikasi sekarang maupun yang akan datang akan disediakan dengan cepat.

4. Membolehkan basis data untuk berkembang dan kebutuhan pemakai untuk berkembang.

\section{METODOLOGI PENELITIAN}

A. Tempat dan Jadwal Penelitian

Untuk melakukan analisis dan mendapatkan data berdasarkan latar belakang masalah yang diajukan maka penulis melakukan penelitian pada masing-masing unit di Politeknik Gorontalo

B. Metode Penelitian

Dasar perancangan yang akandigunakan sebagai bahan kelengkapan data dan informasi adalah:

- Studi Literatur, Pada tahap ini dilakukan pendalaman dan pembelajaran tentang ilmu yang akan digunakan dalam perancangan dan pembuatan sistem. Pendalaman dan pembelajaran ilmu tersebut dapat melalui media buku-buku maupun media internet.

- Metode Wawancara, Pada tahap ini dilakukan pengumpulan data secara langsung melalui wawancara kepada pengelolah Institusi dan Tim IT dari Politeknik Gorontalo.

C. Teknik Pengolahan Data

Pada tahap ini, semua data yang telah didapatkan melalui buku, artikel, maupun media internet serta hasil wawancara dengan pengelolah Institusi akan diolah menjadi sebuah database yang digunakan pada sistem.

D. Alat dan Bahan Penelitian

1) Perangkat Keras

- Processor Intel Core i3 $2,30 \mathrm{GHz}$

- Memory RAM minimal 4 GB

- Harddisk minimal $500 \mathrm{~GB}$

- Printer + Scan

2) Perangkat Lunak

Sistem operasi, bahasa pemrograman, dan beberapa program aplikasi penunjang yang digunakan dalam pembuatan program aplikasi sistem pakar ini adalah:

- Sistem Operasi Windows 10 32/64 bit.

- Aplikasi XAMP 1.7.3 yang di dalamnya terdiri atas :

a. Apache 2.2.4, sebagai web server

b. MySQL 5.0.45, sebagai pengolah database.

c. PHP 5.2.4, sebagai bahasa pemrograman yang digunakan dalam pembuatan web.

d. PHPMyAdmin 2.11.0, sebagai database manager.

- Aplikasi Web Browser, dalam hal ini Mozilla Firefox

E. Teknik Pengujian

Teknik pengujian yang digunakan untuk menguji program apakah sudah bebas dari kesalahan adalah teknik pengujian white box.

F. Tahapan Pembuatan Program

- Pengumpulan Data

Merupakan awal dari pembuatan program dengan menyelenggarakan penelitian untuk mengumpulkan data-data yang diperlukan.

- Perancangan Sistem

Prosedur pengolahan data dan pembuatan model aplikasi secara manual dimana pembuatan model tersebut berdasarkan data-data yang diperoleh dari analisis kegiatan, dilakukan dengan menyelenggarakan penelitian secara tuntas terhadap semua aspek yang berlangsung dalam aplikasi, lalu dituangkan dalam desain sebuah sistem.

- Pembangunan Sistem

Merupakan tahap yang sebenarnya dalam proses pembuatan sistem, sehingga menjadi sebuah program aplikasi yang dapat digunakan.

- Pengujian Sistem

Merupakan proses terakhir dalam tahapan pembuatan program dimana kita perlu menjalankan dan menguji aplikasi tersebut agar dapat memastikan tidak ada lagi kesalahan pengambilan keputusan oleh sistem pakar maupun error coding program. 


\section{IV.HASIL DAN PEMBAHASAN}

A. Uraian Umum Sistem Informasi Manajemen Surat di Politeknik Gorontalo

Sistem Informasi Manajemen Surat di Politeknik Gorontalo adalah suatu sistem manajemen Surat-menyurat pada Politeknik Gorontalo yang harus disimpan/diarsipkan. Semakin lama, surat-surat yang harus diarsipkan juga semakin banyak dan beragam jenisnya. Oleh karena itu diperlukan manajemen kearsipan yang baik, cepat dan efisien. Dengan menggunakan teknologi informasi yang tepat dan baik, keuntungan yang didapat adalah:

1. Proses pengolahan arsip menjadi lebih mudah dan cepat.

2. Proses pencarian data cepat

3. Dokumentasi rapi

4. Proses pencarian mudah

Sistem informasi ini berbasis web yang dapat diakses oleh mahasiswa sebagai user umum tanpa harus melakukan login, Admin sebagai user yang mempunyai hak penuh dalam pengelolaan aplikasi arsip surat ini, dan dosen serta karyawan sebagai user yang dapat menerima informasi surat masuk dan dapat melakukan disposisi apabila surat tersebut ditujukan kepada user tersebut. User admin, dosen dan karyawan harus melakukan login terlebih dahulu untuk mengakses aplikasi ini.

\section{B. Struktur Tabel Database}

Pembuatan database Sistem Informasi Manajemen Surat di Politeknik Gorontalo dalam pengimplementasiannya membutuhkan beberapa tahapan untuk bisa digunakan dalam sebuah aplikasi WEB yakni mulai dari pembuatan database yang kemudian dilanjutkan dengan pembuatan tabel-tabel yang terdapat didalam database. Pada Sistem Informasi Manajemen Surat di Politeknik Gorontalo penulis memberi nama database dengan nama "simansur" dengan tabel diatas database yang dihasilkan dari skema relasi yakni mulai Login, surat masuk, surat keluar, disposisi surat, tujuan surat, klasifikasi surat, list surat, role dan biodata user. Setelah merealisasikan database dan tabel tahapan berikutnya adalah pengenalan karakter yang digunakan untuk dapat memasukan data sesuai dengan karakter data yang akan di input ke dalam table.

1. Tabel t_admin

Tabel t_admin merupakan tabel yang digunakan untuk penyimpanan semua data user dan password dari masing masing user, dengan primary key nya id. Tabel t_admiin dapat dilihat pada table 1 dibawah ini.

TABEL 1

\section{LOGIN ADMINISTRATOR DAN USER}

\begin{tabular}{|c|l|c|c|l|}
\hline No & \multicolumn{1}{|c|}{ Nama Field } & Tipe & Lebar & \multicolumn{1}{|c|}{ Keterangan } \\
\hline 1 & id & Varchar & 10 & Id Pegawai \\
\hline 2 & username & Varchar & 20 & Username Login \\
\hline 3 & password & Varchar & 10 & Password Login \\
\hline 4 & nama & Varchar & 50 & Nama Pegawai \\
\hline 5 & nipy & Varchar & 15 & Nipy Pegawai \\
\hline 6 & level & Varchar & 20 & Level User \\
\hline
\end{tabular}

2. Tabel ref_klasifikasi

Tabel ref_klasifikasi merupakan tabel yang digunakan untuk penyimpanan semua data klasifikasi surat dengan primary key nya id. Tabel t_ref_klasifikasi dapat dilihat pada table 2 dibawah ini.

TABEL 2

KLASIFIKASI SURAT

\begin{tabular}{|c|l|c|c|l|}
\hline No & \multicolumn{1}{|c|}{ Nama Field } & Tipe & Lebar & \multicolumn{1}{|c|}{ Keterangan } \\
\hline 1 & id & Varchar & 10 & Id klasifikasi surat \\
\hline 2 & kode & Varchar & 20 & Kode klasifikasi \\
\hline 3 & nama & Varchar & 10 & Nama klasifikasi \\
\hline 4 & uraian & Varchar & 50 & Uraian klafikasi \\
\hline
\end{tabular}

3. Tabel t_surat_masuk

Tabel $t$ _surat masuk merupakan tabel yang berkaitan dengan semua surat masuk dengan primary key nya id. Tabel t_surat_masuk dapat dilihat pada tabel 3 dibawah ini.

TABEL 3

SURAT MASUK

\begin{tabular}{|c|l|c|c|l|}
\hline No & \multicolumn{1}{|c|}{ Nama Field } & Tipe & Lebar & \multicolumn{1}{c|}{ Keterangan } \\
\hline 1 & id & Varchar & 10 & Id Surat Masuk \\
\hline 2 & kode & Varchar & 10 & Kode Surat Masuk \\
\hline 3 & No_agenda & Varchar & 10 & Nomor Agenda Surat Masuk \\
\hline 4 & Indeks_berkas & Varchar & 10 & Indeks Surat Masuk \\
\hline
\end{tabular}




\begin{tabular}{|c|l|l|l|l|}
\hline 5 & Isi_ringkas & Varchar & 50 & Ringkasan \\
\hline 6 & Dari & Varchar & 50 & Asal Surat \\
\hline 7 & No_surat & Varchar & 10 & Nomor Surat \\
\hline 8 & Tgl_surat & Varchar & 10 & Tanggal Surat \\
\hline 9 & Tg_terima & Varchar & 10 & Tanggal Terima Surat \\
\hline 10 & Keterangan & Varchar & 50 & Keterangan \\
\hline 11 & File & Varchar & 50 & Foto \\
\hline 12 & Pengolah & Varchar & 50 & User Aktif \\
\hline
\end{tabular}

4. Tabel t_surat_keluar

Tabel t_surat_keluar merupakan tabel yang berkaitan dengan semua surat keluar dengan primary key nya id. Tabel t_surat_keluar dapat dilihat pada tabel 4 dibawah ini.

TABEL 4

SURAT KELUAR

\begin{tabular}{|c|l|c|c|l|}
\hline No & \multicolumn{1}{|c|}{ Nama Field } & Tipe & Lebar & \multicolumn{1}{|c|}{ Keterangan } \\
\hline 1 & id & Varchar & 10 & Id Surat Keluar \\
\hline 2 & kode & Varchar & 10 & Kode Surat Keluar \\
\hline 3 & No_agenda & Varchar & 10 & Nomor Agenda Surat Keluar \\
\hline 4 & Isi_ringkas & Varchar & 10 & Indeks Surat Keluar \\
\hline 5 & Tujuan & Varchar & 50 & Tujuan \\
\hline 6 & No_surat & Varchar & 50 & Nomor Surat \\
\hline 7 & Tgl_surat & Varchar & 10 & Tanggal Surat \\
\hline 9 & Tgl_catat & Varchar & 10 & Tanggal Terima Surat \\
\hline 10 & Keterangan & Varchar & 50 & Keterangan \\
\hline 11 & File & Varchar & 50 & Foto \\
\hline 12 & Pengolah & Varchar & 50 & User Aktif \\
\hline
\end{tabular}

5. Tabel t_disposisi

Tabel t_disposisi surat yakni didisposisikan surat yang telah masuk pada Politeknik Gorontalo untuk diteruskan kepada setiap dosen Politeknik Gorontalo atau hanya sebagai tembusan. Tabel disposisi dapat dilihat pada table 5 dibawah ini.

TABEL 5

DISPOSISI SURAT MASUK

\begin{tabular}{|c|l|c|c|l|}
\hline No & \multicolumn{1}{|c|}{ Nama Field } & Tipe & Lebar & \multicolumn{1}{|c|}{ Keterangan } \\
\hline 1 & id & Varchar & 10 & Id Disposisi \\
\hline 2 & Id_surat & Varchar & 10 & Id Surat Masuk \\
\hline 3 & Kpd_yth & Varchar & 10 & Tujuan disposisi \\
\hline 4 & Isi_disposisi & Varchar & 10 & Isi diposisi \\
\hline 5 & Sifat & Varchar & 50 & Sifat disposisi \\
\hline 6 & Batas_waktu & Varchar & 50 & Batas waktu disposisi \\
\hline 7 & Catatan & Varchar & 10 & Catatan tambahan \\
\hline
\end{tabular}

6. Tabel jabatan

Tabel jabatan merupakan tabel yang digunakan untuk penyimpanan semua data jabatan dengan primary key nya id. Tabel jabatan dapat dilihat pada table 6 dibawah ini.

TABEL 6

JABATAN

\begin{tabular}{|c|l|c|c|l|}
\hline No & \multicolumn{1}{|c|}{ Nama Field } & Tipe & Lebar & \multicolumn{1}{c|}{ Keterangan } \\
\hline 1 & Id jabatan & Varchar & 10 & Id Jabatan \\
\hline 2 & nama & Varchar & 20 & Nama Jabatan \\
\hline 3 & jabatan & Varchar & 50 & Jabatan \\
\hline 4 & nipy & Varchar & 15 & Nipy \\
\hline
\end{tabular}




\section{Implementasi}

Form yang telah diimplementasikan dari Pengembangan Sistem Informasi Manajemen Surat Politeknik Gorontalo yaitu:

1. Login

Pada menu Login, terdapat 2 jenis pengguna yaitu login admin yang dapat mengelola penuh website pengarsipan surat ini, serta login user yaitu dosen, karyawan yang hanya dapat mengetahui informasi surat masuk, surat keluar, penyimpanan, surat penting, serta disposisi surat. Gambar 3 memperlihatkan tampilan akses login pada Sistem Manajemen Surat.

\section{Log in to your account.}

\section{Username}

\section{Password}

\section{LOGIN->}

Gbr 3. Halaman Login

2. Halaman Administrator

Menu utama administrator yakni menu yang akan tampil ketika login administrator berhasil dilakukan. Gambar 4 memperlihatkan tampilan utama administrator.

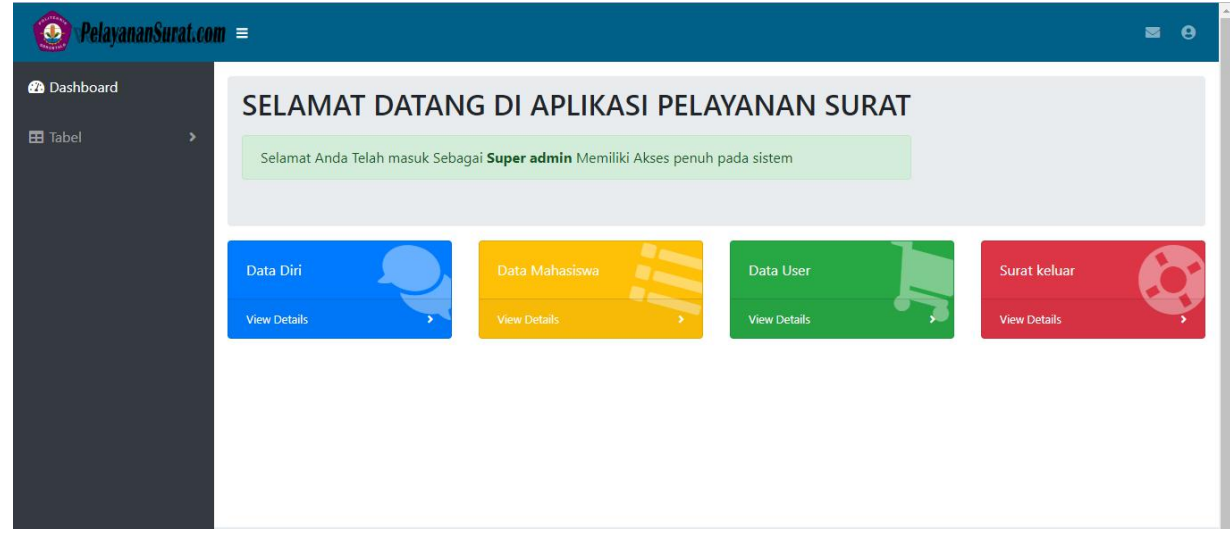

Gbr 4. Halaman Utama Administrator

3. Halaman Tambah Data Diri

Halaman tambah data diri berfungsu untuk menambah data user. Gambar 5 memperlihatkan tampilan tambah data diri. 

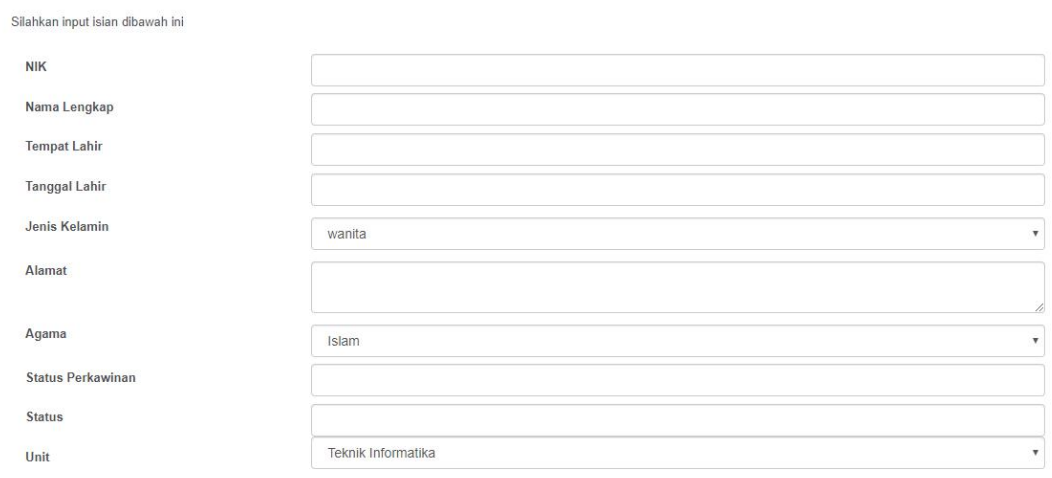

Gbr 5. Halaman Tambah Data Diri

4. Halaman Buat Surat

Halaman buat surat berfungsi untuk membuat surat. Untuk membuat surat, diawali dengan memilih jenis surat. Gambar 6 memperlihatkan tampilan buat surat

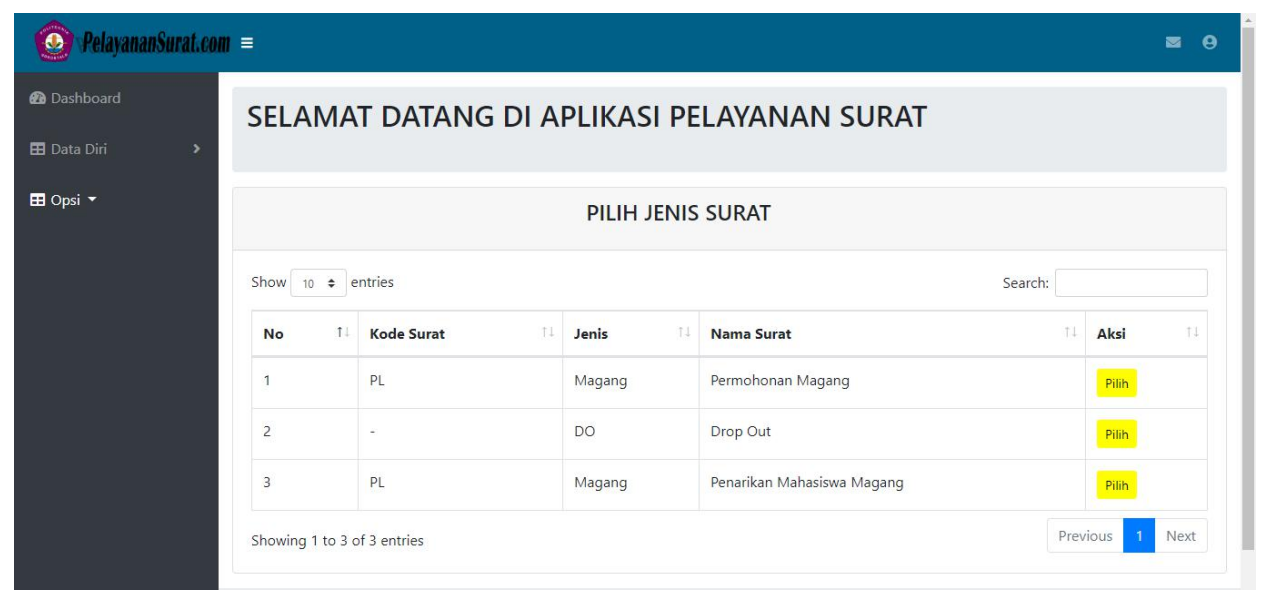

Gbr 6. Halaman Buat Surat

5. Halaman Detail Surat

Pada halaman detail surat, user dapat mengelola surat. Gambar 7 memperlihatkan tampilan detail surat

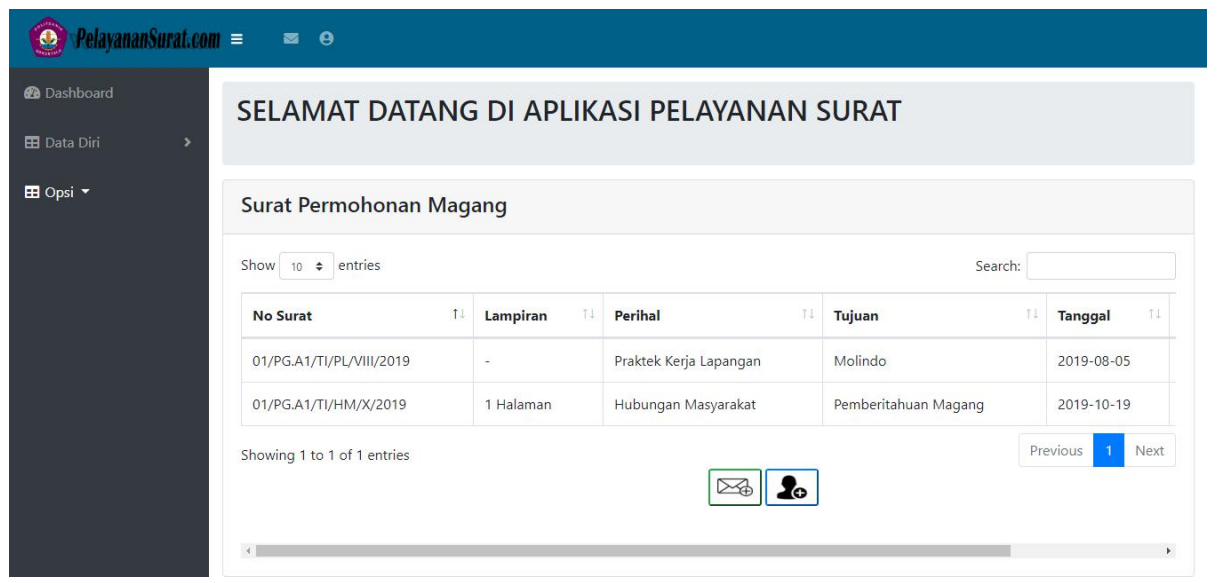

Gbr 7. Halaman Detail Surat 
6. Halaman Edit Surat

Halaman ini berfungsi untuk merubah template surat. Gambar 8 memperlihatkan tampilan edit surat

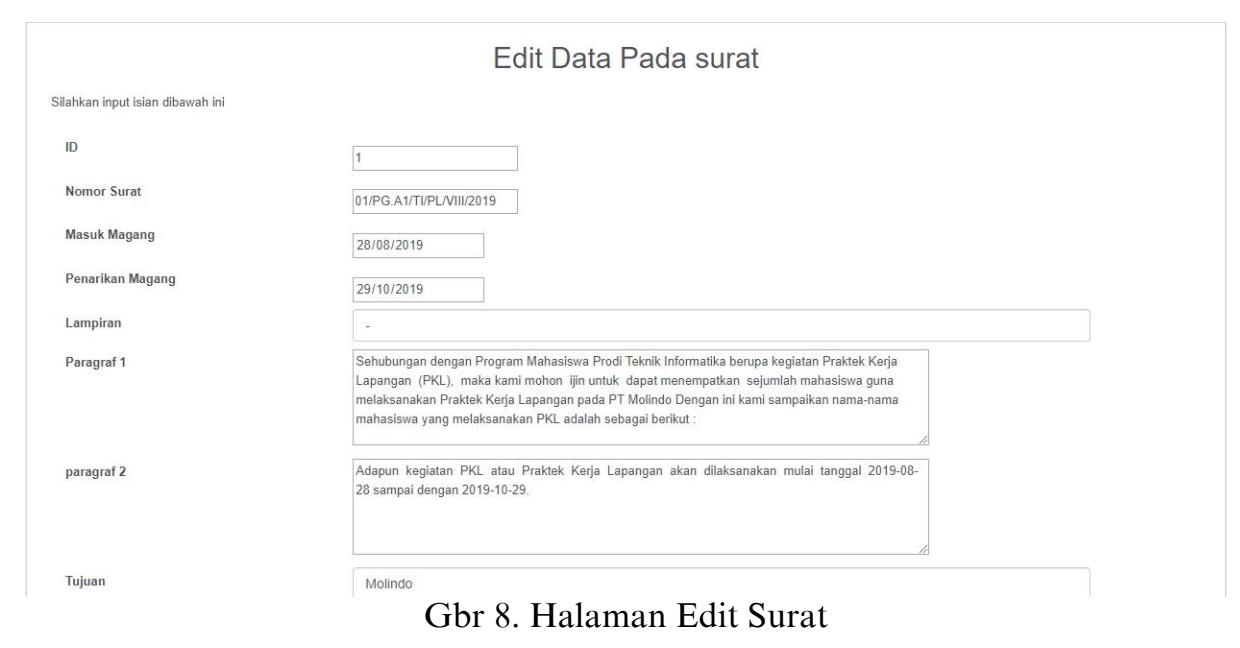

7. Halaman Cetak Surat

Halaman merupakan hasil dari surat yang akan siap dicetak. Gambar 9 memperlihatkan tampilan surat yang siap dicetak

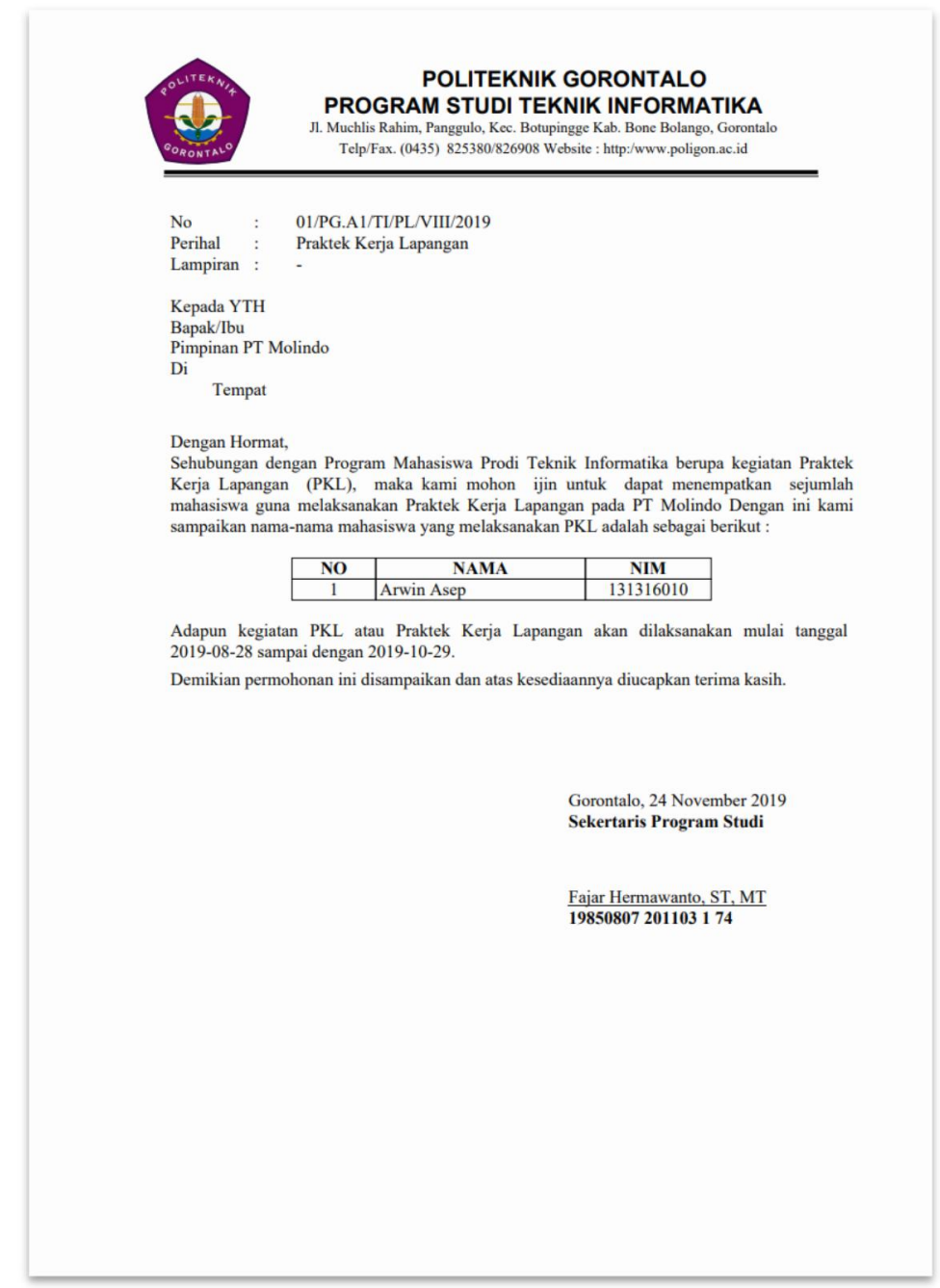

Gbr 9. Halaman Cetak Surat 


\section{KESIMPULAN}

Dengan menerapkan sistem informasi manajemen surat akan memberikan kemudahan dalam pengelolaan surat terutama pada pembuatan template dan nomor surat pada Politeknik Gorontalo. Adapun saran dari hasil penelitian, Sistem Informasi Manajemen Surat Pada Politeknik Gorontalo adalah penggunaan sistem informasi manajemen surat harus dioptimalkan pada semua unit agar hasil yang didapat lebih maksimal. Untuk keberlanjutan penelitian dapat menambahkan beberapa fitur dalam sistem informasi diantaranya aplikasi berbasis mobile.

\section{REFERENSI}

[1] Arbie, E., 2000, Pengantar Sistem Informasi Manajemen, Edisi Ke-7, Jilid 1, Bina Alumni Indonesia, Jakarta.

[2] Gordon B. Davis, 1991, Kerangka Dasar Sistem Informasi Manajemen Bagian 1, PT Pustaka Binamas Pressindo, Jakarta:

[3] Jogiyanto HM., 1999, Analisis dan Disain Informasi: Pendekatan Terstruktur Teori dan Praktek Aplikasi Bisnis, Andi Offset, Yogyakarta

[4] Jogianto2 HM. 2005. Sistem Teknologi Informasi. Andi. Yogyakarta

[5] Junidar, 2012, Perancangan Sistem Informasi Arsip Surat Menyurat di Universitas U'budiyah Indonesia Menggunakan PHP dan MySQL. Banda Aceh

[6] Lani Sidharta, 1995, Pengantar Sistem Informasi Bisnis, P.T. ELEX Media Komputindo, Jakarta:

[7] Mcleod, Raymond, 2001, Sistem Informasi Manajemen, Jakarta, PT. Prenhallindo

[8] Muhyuzir T.D., 2001, Analisa Perancangan Sistem Pengolahan Data, Cetakan Kedua, PT. Elex Media Komputindo, Jakarta

[9] O’Brein, James A., 2005, ”Pengantar Sistem Informasi”, Jakarta: Salemba 4,.

[10] Tata Sutabri, 2005, Sistem Informasi Manajemen, Yogyakarta: Andi 